\title{
A relevância da ludicidade diante da prática pedagógica na educação infantil
}

O presente trabalho visa compreender melhor os fatores que estão direta e indiretamente ligados à importância da prática pedagógica da ludicidade na Educação Infantil. O lúdico é de suma importância na educação infantil, principalmente quando aliado aos jogos e brincadeiras, de maneira que exercitem a criança a pensar e se desenvolver melhor, tendo em vista que, além do aprendizado, o lúdico auxilia na criatividade, desenvolve questões sociais, trabalho em grupo, formação de caráter e personalidade. Nesse viés, busca-se compreender, também, as contribuições da recreação no desenvolvimento das habilidades motoras globais, atribuídas à educação e à formação do cidadão, proporcionando atividades lúdicas e prazerosas desde a Educação Infantil. As informações utilizadas foram obtidas e formalizadas através de pesquisas qualitativas, pois o tema está relacionado à compreensão de fatores que envolvem comportamentos, expectativas, opiniões e resultados. Apesar de o assunto ser muito comum nos dias atuais e discutido de diversas formas por professores, gestores, pais de alunos e interessados, é necessário ter um embasamento através de conhecimentos confirmados por pesquisadores que abordam o assunto de uma maneira mais ampla, clara e objetiva. A ludicidade na Educação Infantil pode ser alcançada de diversas formas, e trabalhada junto a outros fatores importantes, também. Portanto, as informações que deram forma ao conteúdo do trabalho foram utilizadas com o intuito de tratar da importância dos momentos recreativos e lúdicos na educação infantil de forma responsável.

Palavras-chave: Ludicidade; Prática Pedagógica; Educação Infantil.

\section{The relevance of playfulness to the pedagogical practice in early childhood education}

\begin{abstract}
This paper aims to better understand the factors that are directly and indirectly linked to the importance of the pedagogical practice of playfulness in early childhood education. Play is of paramount importance in early childhood education, especially when combined with games and play, so that they exercise the child to think and develop better, considering that, beyond learning, the playful helps in creativity, develops social issues, group work, character and personality formation. In this bias, we also seek to understand the contributions of recreation in the development of global motor skills, attributed to education and training of the citizen, providing playful and enjoyable activities since early childhood education. The information used was obtained and formalized through qualitative research, because the theme is related to the understanding of factors that involve behaviors, expectations, opinions and results. Although the subject is very common today and discussed in various ways by teachers, managers, parents of students and stakeholders, it is necessary to have a foundation through knowledge confirmed by researchers who approach the subject in a broader, clearer and more objective way. Playfulness in early childhood education can be achieved in many ways, and worked on with other important factors, as well. Therefore, the information that shaped the content of the work was used in order to address the importance of recreational and playful moments in early childhood education responsibly.
\end{abstract}

Keywords: Playfulness; Pedagogical practice; Child education.

Topic: Pedagogia (Educação Criança e Adolescente)

Reviewed anonymously in the process of blind peer.
Received: 05/01/2019

Approved: 08/02/2019 


\section{INTRODUÇÃO}

Diante dos estudos mais recentes, pode-se dizer que a recreação e a ludicidade se configuram em instrumentos de grande relevância para o progresso das habilidades motoras globais no desenvolvimento infantil. A Ludicidade, sob o ponto de vista de sua importância para a evolução sensório-motora, tem uma área de atuação bem diversificada e pode ser estudada de diferentes formas, seja por meio dos estudos da teoria ou das práticas recreativas.

A relevância de pesquisar a recreação e a Cultura Lúdica na infância reside em se identificar as contribuições na formação humana e como ela é vivenciada no ambiente escolar. Através dos recursos lúdicos e recreativos como forma de aprendizagem, é possível fazer com que a criança desempenhe melhor suas atividades, obtendo alguns benefícios como a melhora nas relações interpessoais, nas capacidades cognitivas e psicomotoras, na formação de opinião, do caráter e da personalidade.

A infância é a fase da criança em que há mais brincadeira, e é justamente por isso que existe toda esta importância, pois através do universo lúdico, as crianças encontram formas para se expressarem, principalmente quando, através das brincadeiras recreativas e jogos, são criadas situações em que exijam raciocínio e desenvolvimento de vários fatores, além de criação de métodos próprios de comunicação e de entendimento. Ao mesmo tempo, o papel de professor é enxergar o lúdico como uma ótima oportunidade para ser utilizada na educação e trazer bons resultados. 0 educador deve usar este método como forma de ensino, pois assim é possível ter consciência dos benefícios que as brincadeiras e jogos podem proporcionar para os alunos.

Devido a isso, a ludicidade na educação infantil deve ser tratada com seriedade e vista como um benefício que pode trazer resultados positivos em vários aspectos; visto que, através dos jogos e brincadeiras, é possível ter-se como foco o desenvolvimento de pontos importantes e necessários na educação infantil, ou seja, inserir o lúdico como prática cada vez mais frequentes no ensino. Diante disso, questionamos: como o lúdico pode contribuir no aprendizado da criança na educação infantil?.

No contexto apresentado, ao se compreender a importância do lúdico na educação infantil, pode-se apontar, também, os benefícios dos jogos e brincadeiras como contribuição no desenvolvimento da criança; além de entender melhor como a criança recebe informações através do lúdico e como ela se desenvolve a partir das propostas que são dadas.

\section{METODOLOGIA}

Para a presente pesquisa, organizou-se o estudo de forma sistemática, por meio de uma revisão integrativa de literatura de cunho iminentemente qualitativo, exploratório e investigativo (GIL, 2017). A base teórica consistirá em referências de instrumentos de coleta de dados baseados em artigos científicos, livros, revistas cientificas, entre outros. Nesse sentido, as principais ferramentas utilizadas foram a pesquisa bibliográfica, documental, e a observação participante, através da participação em conferências, fóruns, 
seminários, oficinas de formação, reuniões e outros eventos relacionados à Recreação, à Ludicidade, aos jogos e às brincadeiras na Educação Infantil.

A partir da pesquisa exploratório-descritiva, apresentar-se-á o percurso construído com utilização da pesquisa bibliográfica como procedimento metodológico. Esta, enquanto estudo teórico elaborado a partir da reflexão pessoal e da análise de documentos escritos, originais primários denominados fontes, segue uma sequência ordenada de procedimentos (SALVADOR, 2015). Ao iniciar uma pesquisa, a questão fundamental para o pesquisador é fazer uma opção, é decidir o que deve ser recortado, o que é pertinente dentre a vastidão de possibilidades que ele encontra no processo da pesquisa. Delimitar o espaço, o contexto de pesquisa e as ferramentas a serem utilizadas nessa aventura são condições fundamentais para bem percorrer a caminhada.

\section{DISCUSSÃO TEÓRICA}

\section{Atividades Lúdicas, Jogos e Brincadeiras}

É notável que, brincando, as crianças desenvolvem seu raciocínio, criatividade e suas emoções ficam mais participativas, além de aprenderem mais rápido e de forma natural. Para Vigotsky (2007) “As crianças formam estruturas mentais pelo uso de instrumentos e sinais. A brincadeira, a criação de situações imaginárias surgem da tensão entre o indivíduo e a sociedade". Para Vigotsky (2007), o lúdico liberta a criança das amarras da realidade.

As atividades lúdicas podem ser dos mais variados tipos, podendo ser trabalhadas com objetos de uso do cotidiano das crianças, com materiais descartáveis e até mesmo construídos pelos próprios educandos. Os jogos e os brinquedos atraem a atenção das crianças, pois possuem formas, cores, sons e, justamente por isso, tendem a ajudar o docente no seu trabalho durante o desempenho das atividades e no tange ao aprendizado das crianças.

Através das brincadeiras, é possível direcionar as crianças para um ambiente saudável, interessante e de aprendizado constante, unindo a esses fatores a facilidade do aprendizado, criação de habilidades e agregando a vida social e afetiva. Levando em consideração que o lúdico é indispensável em questões psicomotoras e afetivas da criança, é importe enxergá-lo como um recurso útil no método de ensino dos professores, com foco na facilidade do aprendizado, mantendo o prazer da criança e facilidade na prática (JÓIA, 2013).

Portanto, como a recreação e o lúdico são recursos úteis e ao mesmo tempo naturais na vida da criança, devem ser utilizados como base de extrema importância na educação infantil, proporcionando ao aluno a oportunidade de se desenvolver e criar seu caráter e personalidade com base nos aprendizados dinâmicos do dia-a-dia. O presente trabalho visa compreender melhor os fatores que estão direta e indiretamente ligados a Ludicidade na Educação Infantil aliadas a jogos, brinquedos e brincadeiras para o desenvolvimento motor. 
A partir das leituras, foi possível chegar à conclusão de que a Cultura Lúdica é reconhecida, pelos referenciais teóricos, como benéfico à Educação Infantil, os sujeitos afirmam que há contribuições ao aprendizado da criança. Portanto, as informações que deram forma ao conteúdo do trabalho foram utilizadas com o intuito de tratar da importância do lúdico na educação infantil de forma responsável e objetiva (JÓIA, 2013).

Este trabalho pode contribuir na compreensão de como o brincar é concebido na Educação Infantil, pois proporciona às crianças, em todos os aspectos, o seu desenvolvimento integral. Ao se falar de métodos lúdicos que são utilizados como recursos para aprendizados, pode-se compreender que esta prática desenvolve inúmeros benefícios para as crianças.

Vale ressaltar que, segundo Novaes (2012), "o ensino, absorvido de maneira lúdica, passa adquirir um aspecto significativo e efetivo no curso de desenvolvimento da inteligência da criança". Sendo assim, é possível compreender que as brincadeiras, apesar de terem o intuito de divertir, são recursos importantes quando se trata do aprendizado; e não só podem, como devem ser utilizadas para estimular a criança. Para Santos (2016), “(...) os jogos simbólicos, também chamados de brincadeiras simbólicas, ou faz de contas são jogos através dos quais as crianças expressam a capacidade de representarem dramaticamente". Nesse mesmo viés, é lícito afirmar que

a brincadeira se caracteriza por alguma estruturação e pela utilização de regras. A brincadeira é uma atividade que pode ser tanto coletiva quanto individual. Na brincadeira a existência das regras não limita a ação lúdica, a criança pode modificá-la, ausentar-se quando desejar, incluir novos membros, modificar as próprias regras, enfim existe maior liberdade de ação para as crianças.

Diante do que se percebe, as brincadeiras, além de serem recursos ótimos no desenvolvimento e na aprendizagem infantil, têm como missão transformar os sentidos, visto que abrem inúmeras possibilidades de criatividade, imaginação e de aprendizado prazeroso. Esta realidade, paralela à imaginação, favorece os sonhos, a vontade de fazer acontecer, de se envolver mais com aquilo que se identifica, não havendo, assim, limites para criar, planejar e realizar. O brincar transforma a infância da criança, por isso deve ser visto como um fator importante e deve ser cada vez mais utilizado na Educação Infantil.

Com base nessas referências, é possível identificar a importância do lúdico na educação infantil, aliado aos jogos e brincadeiras que visam a auxiliar positivamente o desenvolvimento da criança nesta fase de extrema importância. É necessário levar em consideração que a fase infantil tem total influência na formação de caráter e personalidade do futuro adulto.

A criança é um ser complexo, com características próprias, com uma forma específica de observar o mundo, de modo muito singular, fornecendo perspectivas para transformar o mundo por meio de perspectivas que devem ser entendidas dentro do seu estágio de vida. Nesse sentido, segundo Rousseau (1995), a escola não complementa ou molda a criança; mas proporciona a criança condições para que se desenvolva plenamente. É um conceito variável e que se estabelece nas dimensões psicológica, social e afetiva.

Constata-se que o conceito de infância era ausente até o século XVI, surgindo a partir dos séculos XVII e XVIII. Brougére (2015) destaca, em seus estudos, que essa compreensão passou a ser aceita a partir da 
referida época, momento em que o conceito de infância partiu de construções sociais. Na antiguidade, as crianças eram consideradas adultas em miniatura, por não haver distinção entre o mundo adulto e o mundo infantil, ou seja, a criança 'ingressava na sociedade de adultos'.

Antes, as crianças eram vistas como adultas, mesmo sendo crianças porque o brincar era como se fosse um treino para atividades que, até então, eram adultos que realizavam. Como o exemplo das meninas brincarem de boneca, casinha e, na verdade, já estarem sendo disciplinadas para no futuro, então, serem donas de casa (SILVA, 2005).

Para Modesto (2009), da mesma forma, a humanidade nem sempre viu a criança como um ser particular e, por muito tempo, tratou-a como um pequeno adulto. Hoje, a criança é vista como um sujeito de direitos, situado historicamente e que precisa ter as suas necessidades físicas, cognitivas, psicológicas, emocionais e sociais supridas, caracterizando um atendimento integral e integrado a criança, devendo ter todas as suas dimensões respeitadas.

Assim, entendemos que a criança é diferente do adulto, seu modo de ver o mundo tem suas próprias características. Isso que vai fazer a diferença na primeira etapa de educação na infância, por que no atendimento da Educação Infantil, estabelecido a crianças de 0 a 5 anos, é mais específico o trabalho com a ludicidade, tornando as crianças, ainda que bem pequenas, um ser social, um cidadão com direitos desde os anos iniciais no ambiente escolar. A criança, na idade de Educação Infantil, inicia seu processo de anos iniciais no ambiente escolar, começando a viver uma nova realidade em sua vida. Sendo essencial que o professor, contribua para o seu processo de aprendizagem.

Para Silva (2005), a Educação Infantil torna-se assim um espaço fundamental para a construção de novos conhecimentos, permitindo a interação da criança com outras pessoas e com o mundo dos fatos e dos objetos socioculturais, sendo essas situações de aprendizagem diferenciadas qualitativamente daquelas que perpassam a vida fora da escola.

É no ambiente escolar que as crianças passam a ter um maior contato com outras crianças, é nesse período que também fazem descobertas, na maneira de pensar, jogar, brincar, escutar e de se movimentar. Através disso, é que ocorre a construção de sua identidade e de sua cultura infantil. Nesse sentido, a Educação Infantil tornou-se a primeira etapa da educação básica no Brasil com a promulgação da Lei de Diretrizes e Bases da Educação Nacional (LDBN), em 1996. Cabe dizer que essa divisão foi alterada no ano de 2005, com a sansão presidencial a Lei Federal no 11.114, que define que crianças com seis anos completos devem estar matriculados no Ensino Fundamental I. Dessa forma, a Educação Infantil passou a atender crianças de zero a cinco anos.

Brougére (2015) ainda destaca que, quando a criança inicia sua vida escolar, começa a fazer parte de mais um grupo social, o grupo escolar. E, nesse momento, a mesma necessita aperfeiçoar muitos de seus comportamentos e estruturas, como por exemplo, as afetivas, cognitivas, motoras e sociais, para poderem se adequar ao novo ambiente em que estão inseridas. É natural que a própria criança, através do brincar, passe pelo processo de aperfeiçoamento da construção de sua personalidade, e da sua própria cultura. 
Pensando nisto, percebemos a importância do brincar na Educação Infantil, pois pode proporcionar as crianças uma cultura lúdica rica em brincadeiras, desenvolvimentos, intervenções, garantindo a valorização de conceitos na qual se desenvolvem através de sua própria prática. Para Jóia (2013), reconhecer a infância como um tempo de experiências livres, da construção de hipóteses sobre a realidade, é permitir criar um sujeito crítico, criativo e participativo, pesquisador dentro do ambiente escolar.

Aproveitar a recreação por meio da Cultura Lúdica da própria criança possibilita o seu desenvolvimento integral na qual se cria a identidade, a personalidade desde a infância. Ao se conviver com as crianças, percebe-se que há, por parte delas, um grande interesse pelas histórias infantis. Este fato se evidencia na medida em que se mostram receptivas e motivadas nos momentos destinados as histórias.

\section{A Influência da Cultura Lúdica no Ambiente Escolar}

Pensar ainda que a função da creche e da pré-escola é apenas cuidar de crianças é um erro. Pois a primeira função das instituições de Educação Infantil é estimular o desenvolvimento integral do educando. Nesse contexto, o brincar é essencial; pois, por meio de atividades lúdicas, a criança ordena o pensamento, desenvolve a criatividade e autoestima e aperfeiçoa a capacidade de resolver problemas (TAVARES, 2017).

As escolas de educação infantil podem ser vistas como um local que favorece o desenvolvimento infantil e o referencial da Educação Infantil ao contemplar a brincadeira como uma das questões presentes durante a vivência para as crianças que fazem parte deste universo. Assim, tais instâncias já apontam a importância dessa ação para o desenvolvimento e para o aprendizado da criança.

O brincar dentro da escola, através da inclusão do lúdico nas propostas pedagógicas, possibilita o desenvolvimento infantil; sobretudo, quando se trata da questão do imaginário e da aquisição dos símbolos, momento quando a criança faz associações e recria no momento em que brinca proporcionando novas vivências e, por consequência, seu desenvolvimento (TAVARES, 2017).

A utilização do brinquedo com a finalidade pedagógica na educação infantil é importante para se pensar na relevância existente na utilização desses materiais no processo de desenvolvimento da criança e de sua aprendizagem. Quando se trata de crianças no nível pré-escolar, o fato de que elas aprendem de modo intuitivo durante os processos de interação com os brinquedos e com as ações que acontecem ao seu redor pode interferir de forma positiva no momento dessa aprendizagem. Vale-se muito da organização de tempo e espaço nas atividades com as crianças, ao passo que isso pode ajudar muito no desenvolvimento do educando, aprendendo a ter noção de espaço, tempo e a não ser tão dependente de adultos.

Uma boa organização do espaço de tempo é fundamental para que as crianças se familiarizem com o funcionamento da sala-ambiente bem como de suas atividades, participando mais ativa e autonomamente. O professor precisa gerir bem o tempo, devendo considerar que algumas crianças são mais lentas para desenvolver determinadas atividades e outras ainda se mostram desinteressadas ou agitadas, fazendo com que se altere a rotina. $O$ mediador precisa ser sensível e flexível o suficiente para trocar as atividades de acordo com a sua necessidade e o seu interesse (JÓIA, 2013). 
A infância é a idade das brincadeiras. Por meio dela, as crianças satisfazem grande parte de seus desejos e interesses particulares. "O aprendizado da brincadeira, pela criança, propicia a liberação de energias, a expansão das criatividades, fortalece a sociabilidade e estimula a liberdade do desempenho" (GARCIA et al., 2011).

Segundo Garcia et al. (2011), a palavra 'brincar' não se relaciona apenas às atividades feitas com as crianças, pois em todas idades, as pessoas brincam. Nesse sentido, há uma diferença ao se considerar os momentos em que as crianças brincam de modo espontâneo no ambiente escolar, com mais frequência e liberdade, visto que, quando brincam, observa-se a satisfação que elas experimentam ao participar das atividades.

Sinais de alegria, risos, certa excitação que são componentes desse prazer pueril; embora a contribuição do brincar vá bem mais longe do que meros impulsos parciais. Pode-se dizer que a Cultura Lúdica, na escola, tem como objetivo ensinar as crianças brincando; de modo que os prepare para a vida e, em conjunto, para que tenham liberdade de ação, possibilidade de repetição das experiências; podendo, destarte, obter a realização simbólica dos seus desejos.

Considerando esses aspectos da cultura lúdica, percebe-se diferentes abordagens sociológicas, psicológicas e antropológicas que reforçam essa influência no ambiente escolar. Na abordagem sociológica, os aspectos analisados na brincadeira tratam do processo de socialização infantil, da interação entre as crianças, das formas de participação de cada elemento, do desempenho de papeis, do nível de aceitação de cada criança, das atitudes, da liderança, entre outros.

Na psicológica, as brincadeiras são analisadas de acordo com o significado de objetos e das ações para cada criança, das expectativas do grau de esforço realizado para que as ações sejam valorizadas pelo grupo. Na antropológica, procura-se acompanhar a trajetória dos jogos infantis em relação às influências étnicas, à zona de dispersão, às variações que ocorrem em virtude de tempos e espaços etc. (TAVARES, 2017).

Tais abordagens combinam brincadeiras, relacionando-os com inúmeros aspectos, como com a própria recreação, com desenvolvimento de habilidades sociais, projeções psíquicas, contribuição para o desenvolvimento físico e mental da criança. Por isso, todas as abordagens são válidas, pois ampliam os conhecimentos e a compreensão da criança e de seu contexto no ambiente escolar.

\section{Jogos e Brincadeiras na Educação Infantil}

A Educação Infantil sofreu consideráveis modificações, passou por processos de reconhecimento e construção de uma nova identidade, assumindo um papel importante na educação e no processo de socialização, atualmente vem se destacando em nossa sociedade. A infância não é apenas um período entre o nascimento e o início da vida adulta, está relacionada ao estado e a condição de uma criança, envolve a qualidade desses anos de vida, implicando num espaço separado e seguro, no qual pode crescer, brincar e se desenvolver.

A criança passa a aprender novos comportamentos, adapta-se a novas situações, desde que lhe sejam dadas condições favoráveis, pois o ambiente em que se vive é o principal elemento de determinação 
de seu desenvolvimento através das trocas recíprocas que se estabelecem entre a criança e o meio. 0 desenvolvimento é um processo de conhecimento e de mudança de comportamento que ocorrem em fases ao longo da vida. Cada fase é marcada por acontecimentos particulares, por características especificas que estão intrinsecamente relacionadas às áreas motoras, cognitivas e afetivas. Para que a criança tenha um desenvolvimento adequado, é fundamental que estes três domínios sejam conjuntamente trabalhados e de modo harmônico (BROUGÉRE, 2015).

A criança explora o ambiente conforme sua capacidade de se movimentar; portanto, o movimento, objeto de estudo da educação física, é constituído historicamente pelo homem e se expressa através de inúmeras práticas corporais presentes na cultura, tais como: jogos, brincadeiras, danças, lutas, esportes, ginásticas, entre outras. Essa produção, denominada de cultura corporal, constitui o conhecimento de desenvolvimento na educação infantil e ao longo de todas as etapas da Educação Básica.

A aprendizagem na Educação Infantil deve ser estimulada em cada fase de desenvolvimento da criança. Ao passo que, desde a tenra idade, as crianças as necessitam de ter uma rotina planejada, estruturada e organizada para melhor desenvolver-se. Assim, o lúdico na infância faz parte do processo da construção de conhecimento da criança. As brincadeiras realizadas, na educação infantil, devem ter planejamento, possibilitando o desenvolvimento integral de suas habilidades motoras, mentais e sociais básicas; fundamental para o crescimento saudável (TAVARES, 2017).

A atividade lúdica envolve, o brinquedo (objeto), brincadeira (ação) e o jogo (ação de regras), e 22 acontece em determinado tempo e lugar, livre e espontaneamente, com a participação de uma ou mais crianças. Distingue-se pelo prazer e satisfação que proporciona às crianças. A importância da atividade lúdica não se restringe apenas a criança, mas estende-se à sua família e a sociedade. Sendo que o cuidar da criança faz parte do seu contexto educativo, fazendo-se necessária a cooperação de diferentes profissionais. A formação do profissional de Educação Infantil deve ser qualificada, a falta de uma metodologia adequada para o desenvolvimento de cada atividade impede que a criança tenha alcance o seu desenvolvimento.

As aulas de Educação Física, na Educação Infantil, produzem o conhecimento por meio de brincadeiras, atividades lúdicas do qual a criança, passe pela transformação na sua totalidade desenvolvimento integral da criança. Segundo Novaes (2012), os movimentos são de grande importância para a vida do ser humano. É através dos movimentos que o ser humano age sobre o meio ambiente, para alcançar objetivos desejados ou satisfazer suas necessidades.

\section{CONCLUSÕES}

Consoante, pode-se verificar, no decorrer do trabalho, a Educação Infantil passou a ser de fundamental importância no cotidiano das crianças; pois muitas famílias, em que pais trabalham, matriculam suas crianças na Educação Infantil. Assim o ambiente escolar passa a ser um segundo lar das crianças, no qual aprendem valores humanos, éticos e culturais. O Referencial Curricular Nacional para a Educação Infantil traz que brincadeira recreativa é uma linguagem que mantém um vínculo essencial com aquilo que é o "não brincar" (BRASIL, 1998). 
Desse modo, os documentos norteadores da educação brasileira salientam, ainda, que a brincadeira é uma ação que ocorre no plano da imaginação, o que implica que aquele que brinca tenha o domínio da linguagem simbólica. A Educação Infantil é uma fase muito importante na infância, na qual pode-se ter o desenvolvimento integral da criança.

A Cultura Lúdica, além de auxiliar no desenvolvimento sensório-motor, é composta de certo número de esquemas que permitem iniciar e organizar o ato de brincar, já que se trata de produzir uma realidade diferente daquela da vida cotidiana. A Cultura Lúdica é algo que vem da própria criança, ou seja, é sua identidade, visto que, em cada parte do mundo, as crianças têm sua maneira de se divertir por meio de algo que traga alegria e encanto para elas. Destarte, a cultura lúdica faz parte do cotidiano de todos, independente se são adultos ou crianças.

A Educação Infantil é o início da formação humana, por isso se busca muito mais do que apenas aplicação de conteúdo. Então, não se pode imaginar uma turma com crianças paradas, sem ações. Nessa primeira etapa da educação, o mediador do conhecimento deve preparar as crianças para inúmeras situações da vida. A instituição que fornece Educação Infantil deve pensar no que seja eficaz para as crianças dentro de suas realidades, espaços e concepções.

Diante disso, é possível verificar que os Centros de Educação Infantil que têm uma filosofia que respeita a ludicidade e as diferentes etapas de desenvolvimento infantil conduz os sujeitos de modo a organizarem suas rotinas temporais para o brincar de acordo com a necessidade das crianças. De modo prático, dirige-se especial comentário para as brincadeiras relacionadas às cantigas de rodas, pontos altos da Educação Infantil, pois desperta aproximação e um bom convívio social.

A Cultura Lúdica na infância é algo que a própria criança elabora na relação com o outro e, quando auxiliada, é uma ferramenta de ensino com a qual as crianças aprendem brincando. Portanto, o que se espera é que os que atuam na educação infantil compreendam que brincar e usar as atividades lúdicas é a maneira de se aprender na infância. Ainda no que concerne aos docentes, é igualmente importante prezar por uma educação de qualidade e, para tanto, os professores devem pensar com zelo se serão dedicados à Educação Infantil, dando continuidade constante a sua formação especializada para o trabalho com os educandos infantes; ou se atuarão em outros campos da pedagogia em geral.

Corroborando com as expectativas iniciais e respondendo ao questionamento de pesquisa, assinalase que a ludicidade pode ser entendida como um dos fatores motivadores e um dos requisitos importantíssimos para o desenvolvimento na infância, como também para a permanência e para o gosto pela escola; não devendo, portanto, ser esquecido em nenhuma fase da vida escolar, pelo contrário, tem que ser intensificado e diversificado a cada instante devido às suas valiosas contribuições para o ensinoaprendizagem na educação infantil.

\section{REFERÊNCIAS}

ALMEIDA, M. T. P.. O brincar na educação Infantil. EF Artigos, Natal, v.3, n.1, 2005.
BRASIL. Ministério da Educação e do Desporto. Lei de Diretrizes e Bases da Educacional. Brasília: DOU, 1996. 
BRASIL. Ministério da Educação e do Desporto. Referencial Curricular para a Educação Infantil: Brincar. Brasília: MEC, 1998.

BRASIL. Ministério da Educação e do Desporto. Referencial Curricular para a Educação Infantil: Brincar. Brasília: MEC, 1998.

BROUGÉRE, G.. Jogo e Educação. 3 ed. Porto Alegre: Artes Médicas, 2015.

GARCIA, R. M. R.; MARQUES, L. A.. Brincadeiras Cantadas. 4 ed. Porto Alegre: Kuarup, 2011.

GIL, A. C.. Como elaborar projetos de pesquisa. 6 ed. São Paulo: Atlas, 2017.

JÓIA, A.. Educação Infantil em Caieiras: um estudo sobre as concepções e práticas de atendimento às crianças pequenas presentes em creches municipais. Dissertação (Mestrado) Pontifícia Universidade Católica de São Paulo, São Paulo, 2013.

MODESTO, R. D. L.. O lúdico como processo de influência na aprendizagem da educação infantil. Monografia
(Especialização em Educação) - Universidade Federal Tecnológica do Paraná, Medianeira, 2009.

NOVAES, J .C.. Brincando de roda. 4 ed. Rio de Janeiro: Agir, 2012.

OLIVEIRA, V. B.. O brincar e a criança do nascimento aos seis anos. Petrópolis: Vozes, 2000.

ROUSSEAU, J. J.. Emílio ou Da educação. São Paulo: Martins, 1995.

SALVADOR, A. D.. Métodos e técnicas de pesquisa bibliográfica. 6 ed. Porto Alegre: Sulina, 2015.

SANTOS, S. M. P.. O lúdico na formação do educador. 9 ed. Petrópolis: Vozes, 2016.

SILVA, A.. Reestruturação curricular: teoria e prática no cotidiano da escola. Petrópolis: Vozes, 2005.

TAVARES, A.. Brincar é coisa séria. 4 ed. São Paulo: Abril, 2017.

VYGOTSKY, L. S.. Formação social da mente. São Paulo: Martins Fontes, 2007.

A CBPC - Companhia Brasileira de Produção Científica (CNPJ: 11.221.422/0001-03) detém os direitos materiais desta publicação. Os direitos referem-se à publicação do trabalho em qualquer parte do mundo, incluindo os direitos às renovações, expansões e disseminações da contribuição, bem como outros direitos subsidiários. Todos os trabalhos publicados eletronicamente poderão posteriormente ser publicados em coletâneas impressas sob coordenação da Sustenere Publishing, da Companhia Brasileira de Produção Científica e seus parceiros autorizados. Os (as) autores (as) preservam os direitos autorais, mas não têm permissão para a publicação da contribuição em outro meio, impresso ou digital, em português ou em tradução. 